\title{
Synergistic efficacies of thymoquinone and standard antibiotics against multi-drug resistant isolates
}

\author{
Ayed A. Dera, PhD, Irfan Ahmad, PhD, Prasanna Rajagopalan, PhD, Mesfer Al Shahrani, PhD, Ahmed Saif, PhD, \\ Mohammad Y. Alshahrani, PhD, Yasser Alraey, PhD, Ahmad M. Alamri, PhD, Sultan Alasmari, PhD, \\ Mohammed Makkawi, PhD, Ali G. Alkhathami, PhD, Gaffar Zaman, MD, Abdulrahim Hakami, PhD, \\ Razan Alhefzi, MSc, Mohammad A. Alfhili, PhD.
}

\begin{abstract}
الأهداف : هذه الدراسة تستكشف النشاط المضاد للبكتيريا للثايمو كينون وهو المستخلص من حبة البركة.

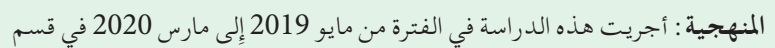

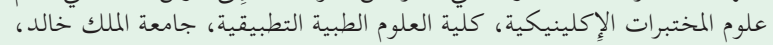

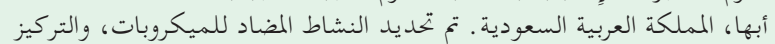

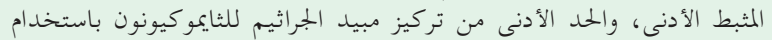

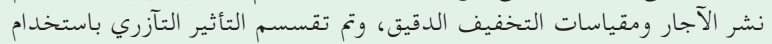

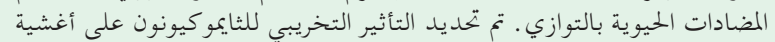

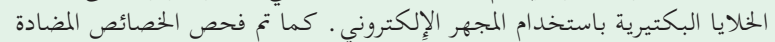

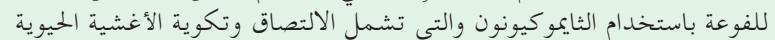

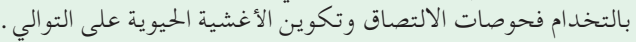

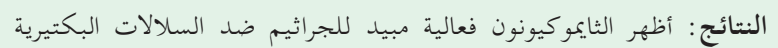

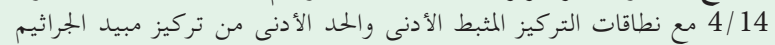

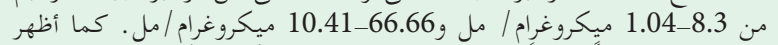

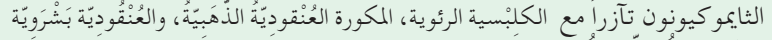

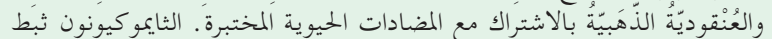

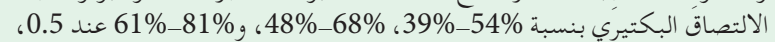

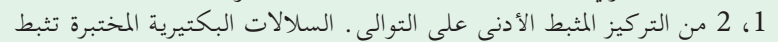

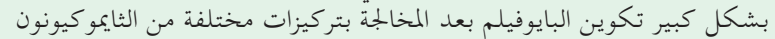

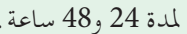

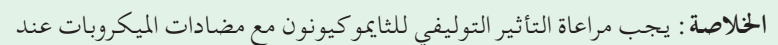

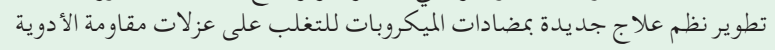
المتعددة.
\end{abstract}

Objectives: To explore the antibacterial activity of thymoquinone (TQ), a quinone extracted from Nigella sativa.

Methods: This study was conducted from May 2019 to March 2020 at the Department of Clinical Laboratory Sciences, College of Applied Medical Sciences, King Khalid University, Abha, Saudi Arabia. The antimicrobial activity, minimum inhibitory concentration (MIC), and minimum bactericidal concentration (MBC) of TQ were determined using an agar well diffusion method and broth microdilution assays, and the synergistic effect was evaluated using antibiotics in parallel. The disruptive effect of TQ on bacterial cell membranes was determined using scanning electron microscopy. The antivirulence properties of TQ, which include adherence and biofilm formation, were also investigated using adherence and biofilm formation assays, respectively.

Results: Thymoquinone demonstrated bactericidal efficacy against $4 / 14$ bacterial strains, with MIC range of $1.04-8.3 \mu \mathrm{g} / \mathrm{mL}$ and and MBC range of 10.41-66.66 $\mu \mathrm{g} /$ $\mathrm{mL}$. Thymoquinone showed synergism against Klebsiella pneumoniae, Staphylococcus epidermidis (American Type Culture Collection 12228), Staphylococcus aureus, and Staphylococcus epidermidis in combination with the tested antibiotics. Thymoquinone inhibited bacterial adhesion by $39 \%-54 \%, 48 \%-68 \%$, and $61 \%-81 \%$ at $0.5 \times$ MIC, $1 \times \mathrm{MIC}$, and $2 \times \mathrm{MIC}$, respectively. The tested bacterial strains significantly inhibited biofilm formation after treatment with various concentrations of TQ for 24 and 48 hours.

Conclusion: The combinatory effect of TQ with antimicrobials should be considered when developing new antimicrobial therapy regimens to overcome multidrugresistant.

Keywords: thymoquinone, antibacterial, adhesion, biofilm formation, synergism

Saudi Med J 2021; Vol. 42 (2): 196-204 doi: 10.15537/smj.2021.2.25706

From the Department of Clinical Laboratory Sciences, Central Research Laboratory (Dera, Ahmad, Rajagopalan, Al Shahrani, Alshahrani, Alraey, Alamri, Alasmari, Makkawi, Alkhathami, Zaman, Hakami, Alhefzi), College of Applied Medical Sciences, King Khalid University, and From the Department of Clinical Laboratory Sciences, Central Research Laboratory (AlAmri), College of Applied Medical Sciences, and Cancer Research Unit, King Khalid University, Abha; from the Department of Clinical Laboratory Sciences (Saif), College of Applied Medical Sciences, Najran University, Najran; and the Chair of Medical and Molecular Genetics Research, Department of Clinical Laboratory Sciences (Alfhili), College of Applied Medical Sciences, King Saud University, Riyadh, Kingdom of Saudi Arabia.

Received 14th November 2020. Accepted 14th January 2021.

Address correspondence and reprint request to: Dr. Ayed A. Dera, Department of Clinical Laboratory Sciences, College of Applied Medical Sciences, King Khalid University, Abha, Kingdom of Saudi Arabia.E-mail: ayedd@kku.edu.sa

ORCID ID: https://orcid.org/0000-0002-6248-8983 
$\mathrm{A}^{\mathrm{n}}$ ntibiotic resistance has become a major health issue over the past decade due to the rapid growth of multidrug-resistant (MDR) microbes. ${ }^{1}$ Antimicrobial drugs are effective in bacterial infection control. However, microbes have the ability to develop resistance to several active antimicrobials. ${ }^{2}$ Due to the emergence of multidrug resistance and the insufficiency of new antimicrobials, novel and innovative approaches to combat MDR bacteria are crucial. 3,4 However, bacteria efficiently develop resistance to antimicrobials soon after they have been introduced, and the majority of antibiotics have side effects. ${ }^{5}$ Therefore, searches for new drugs or combinations with less toxicity and uncompromised efficacy against resistant strains are continually evolving. ${ }^{6,7}$ Nonetheless, the issue of bacterial resistance to antibiotics was resolved by the uncovering of new antibiotics, like glycopeptides, aminoglycosides, and macrolides, as well as by chemically modifying existing medicines. ${ }^{1}$

A potential strategy to minimize microbial resistance is the administration of antimicrobials in combination with naturally available compounds. ${ }^{1,8}$ Phytochemicals synergistically enhance the effect of traditional

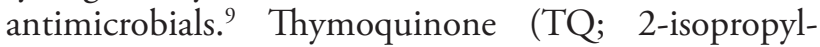
5-methyl-1,4-benzoquinone) is an essential active compound of Nigella sativa ( $N$. sativa) L. seeds (black seed), which have been traditionally used for decades in the Middle East, Northern Africa, and India as a natural remedy for many contagious diseases such as bronchitis, pulmonary infection, cough, influenza, and fever. ${ }^{10-11}$ Thymoquinone exerts various pharmacological effects and has antiinflammatory, anticancer, antidiabetic, antiasthmatic, hypolipidemic, antihypertensive, nephroprotective, and antimicrobial activities. ${ }^{12-16}$

The antibacterial effects of TQ and other $N$. sativa extracts have been determined against Staphylococcus aureus (S. aureus), Pseudomonas aeruginosa (P. aeruginosa), Listeria monocytogenes, and Escherichia coli (E. coli). ${ }^{17-19}$ Thymoquinone exerts inhibitory effects against gram-negative and gram-positive bacteria. ${ }^{20} \mathrm{~A}$ diethyl ether extract of $N$. sativa showed synergy with streptomycin and gentamicin and an additive effect with erythromycin, streptomycin, doxycycline, tobramycin, nalidixic acid, chloramphenicol, ampicillin, cotrimoxazole, and lincomycin. ${ }^{21}$ Furthermore, both

Disclosure. This study was funded by the Deanship of Scientific Research, King Khalid University, Abha, Kingdom of Saudi Arabia (Grant Number: G.R.P-3-40). antibiotic-sensitive and MDR gram-positive and gram-negative bacterial isolates are susceptible to $N$. sativa extracts. ${ }^{22}$ This study aimed to further elucidate the potential effect of TQ against clinically significant bacteria by investigating the antibacterial effect of TQ alone and in combination with different antibiotics against drug-resistant isolates.

Methods. This is an experimental study which was conducted from May 2019 to March 2020 in the Department of Clinical Laboratory Sciences, College of Applied Medical Sciences, King Khalid University, Abha, Saudi Arabia.

Organisms and chemicals. The antibacterial effect of TQ was examined using pathogenic strains, including the gram-negative bacteria $P$. aeruginosa (American Type Culture Collection [ATCC] 27853), E. coli (ATCC 25922), E. coli, Salmonella typhi, Pseudomonas sp., Klebsiella pneumoniae (K. pneumoniae), and Shigella $s p$.), and the gram-positive bacteria Enterococcus faecalis (ATCC 29212), S. epidermidis (ATCC 12228), S. aureus, S. saprophyticus, S. epidermidis, Streptococcus pyogenes, and Mycobacterium smegmatis. Gentamycin, ofloxacin, tetracycline, penicillin, chloramphenicol, nalidixic acid, and TQ were purchased from Sigma (Sigma-Aldrich, Switzerland).

Antimicrobial susceptibility assays. The antimicrobial activity of the compounds was evaluated using an agar well diffusion method. The bacterial culture was inoculated in lysogeny broth and incubated at $37^{\circ} \mathrm{C}$ for $3 \mathrm{~h}$ (hours). The turbidity of the inoculum was consequently adjusted using phosphate-buffered saline (PBS) to be equivalent to $0.5 \mathrm{McF}$ arland's standard. Then, $20 \mu \mathrm{L}$ of TQ $(50 \mu \mathrm{g} / \mathrm{mL})$ was transferred into each well of the Petri dishes, which were then incubated aerobically at $37^{\circ} \mathrm{C}$ for 24 hours (h). The width of the zone of inhibition of bacterial growth surrounding each well was calculated in millimeters, as previously described. ${ }^{23}$

Determination of minimum inhibitory concentration (MIC). The MICs of TQ against the bacterial strains were determined by broth microdilution assays using TQ concentrations of $0.024-50 \mu \mathrm{g} / \mathrm{mL}$. Two-fold dilutions of TQ $(100 \mu \mathrm{L})$ were pipetted into the wells of a sterile flat-bottomed 96-well plate for each strain under test. The initial inoculum concentration for each strain was $1.5 \times 105$ colony-forming units $/ \mathrm{mL}$. The control wells contained the bacterial inoculum only. The plate was incubated aerobically $37^{\circ} \mathrm{C}$ for $24 \mathrm{~h}$. The lowest TQ concentration that exhibited neither turbidity nor visible bacterial growth after the 24-h incubation was considered the MIC. 
Determination of minimum bactericidal concentration $(M B C)$. After the $24-\mathrm{h}$ incubation, $100 \mu \mathrm{L}$ of inoculum from each well of the broth microdilution assay plate was sub-cultured on Mueller-Hinton agar (MHA) plates, which were then incubated for $24 \mathrm{~h}$. The minimum concentration of TQ that resulted in no bacterial growth was considered the MBC.

Synergistic antimicrobial assays. The synergistic antimicrobial activity of antibiotics (gentamycin, ofloxacin, tetracycline, penicillin, chloramphenicol, and nalidixic acid) in combination with TQ was investigated. Bacterial strains at a turbidity of 0.5 McFarland's standard were spread on MHA plates. The specific antibiotic discs, which had been kept aerobically at $37^{\circ} \mathrm{C}$ for $24 \mathrm{~h}$, were separately soaked in $5 \mu \mathrm{L}$ of TQ (at the MBC value) and placed on the inoculated MHA plates. Then, the plates were incubated aerobically at $37^{\circ} \mathrm{C}$ for $24 \mathrm{~h}$. The inhibition zones formed by TQ in combination with the selected antibiotics after overnight incubation were calculated, as previously described. ${ }^{24}$

Scanning electron microscopy (SEM). Scanning electron microscopy was used to investigate the effect of TQ on cell morphology. ${ }^{25}$ Scanning electron microscopy sample preparation was initially carried out in centrifuge tubes. Then, the bacterial specimens were instantly fixed in $2.5 \%$ (wt/vol) phosphate-buffered glutaraldehyde $(\mathrm{pH} 7.4)$ at $4^{\circ} \mathrm{C}$ for $4 \mathrm{~h}$, followed by post-fixation in $1 \%$ phosphate-buffered osmium tetroxide $(\mathrm{pH} 7.4)$ for $1 \mathrm{~h}$. After washing and dehydration in ascending grades of ethanol, critical-point drying was performed using an EMitech K850 critical-point dryer. The samples were mounted on aluminum mounts with silver glue and then sputtered with a gold coat using a BOC Edwards Scancoat sputter coater. The specimens were examined using a JSM-6390LV scanning electron microscope (Jeol Ltd., Japan). ${ }^{26}$

Adherence assay. Bacterial adherence was assessed as described elsewhere. ${ }^{27}$ Briefly, $100 \mu \mathrm{L}$ of the bacterial cells under test (optical density at $610 \mathrm{~nm}\left[\mathrm{OD}_{610 \mathrm{~nm}}\right]=0.01$ ) grown in Roswell Park Memorial Institute (RPMI), New York, United States in America (USA) 1640 media and buffered with $0.165 \mathrm{M}$ morpholinepropanesulphonic acid (MOPS) (Sigma-Aldrich, MO, USA) at pH 7.0 were loaded into all wells of a 96-well plate. Then, the bacterial cells were treated with different concentrations of TQ $(0.5 \times \mathrm{MIC}, 1 \times \mathrm{MIC}$, and $2 \times \mathrm{MIC})$ and incubated for $6 \mathrm{~h}$ at $37^{\circ} \mathrm{C}$. Untreated bacterial cells were used in each set of experiments as negative controls. Following incubation, the media were discarded, and each well was rinsed twice with $200 \mu \mathrm{L}$ PBS to eliminate the non-adherent bacterial cells. Then, 100 $\mu \mathrm{L}$ of Alamar blue at an absolute concentration of
5\% in RPMI 1640 media was loaded into each well, followed by incubation at $37^{\circ} \mathrm{C}$ for $6 \mathrm{~h}$. The amount of fluorescence was measured at 555 and $585 \mathrm{~nm}$ for excitation and emission, respectively, using a Synergy HT microplate reader (BioTek Instruments, VT, USA).

Biofilm formation assay. Biofilm production was assessed by the inoculating the tested bacterial cells suspensions $\left(\mathrm{OD}_{610 \mathrm{~nm}}=0.01\right)$ grown in RPMI 1640 media buffered with 0.165 M MOPS ( $\mathrm{pH} 7.0$ ) into the wells of a sterile flat-bottomed 96-well plate, and the plate was incubated for $6 \mathrm{~h}$ at $37^{\circ} \mathrm{C} .{ }^{28}$ Thereafter, the culture medium was carefully removed without disturbing the formation of biofilm. Then, different TQ concentrations $(0.5 \times \mathrm{MIC}, 1 \times \mathrm{MIC}$, and $2 \times \mathrm{MIC})$ were prepared in fresh RPMI 1640 medium and loaded into the wells. Untreated bacterial cells were used as negative controls in each set of experiments. The 96-well plate was further incubated at $37^{\circ} \mathrm{C}$, and the effect of TQ on biofilm formation was assessed after $24 \mathrm{~h}$ and $48 \mathrm{~h}$, as previously described. ${ }^{29}$

Statistical analysis. Each investigation was conducted in triplicate, and the results were presented as means \pm standard deviation (SD). GraphPad Prism software v6.0 (GraphPad, CA, USA) was used to perform the statistical analyses. One-way analysis of variance with Dunnett's multiple comparison test was used to compare the mean between different groups with that of the control. $P$-values $<0.05$ were considered statistically significant.

Results. Antibacterial activity of TQ. Thymoquinone exerted a bactericidal effect on 4/14 strains, with MICs of $1.04-8.3 \mu \mathrm{g} / \mathrm{mL}$ and MBCs of $10.41-66.66 \mu \mathrm{g} / \mathrm{mL}$ (Table $1 \&$ Figure 1). This effect was almost indistinguishable from the tested antibiotics (ofloxacin, gentamycin, tetracycline, penicillin, chloramphenicol, and nalidixic acid). The gram-negative bacteria E. coli ATCC 25922, P. aeruginosa ATCC 27853, Pseudomonas sp., Salmonella typhi, Shigella sp., and E. coli were resistant to TQ. However, for gram-positive bacteria, only Enterococcus faecalis ATCC 29212, M. smegmatis, S. saprophyticus, and $S$. pyogenes appeared resistant to TQ.

Synergism action. For gram-positive bacteria, TQ showed synergism in combination with gentamicin and penicillin against S. epidermidis ATCC 12228; with ofloxacin, tetracycline, and chloramphenicol against $S$ aureus; and with ofloxacin and penicillin against S. epidermidis. For gram-negative bacteria, TQ showed synergism with gentamicin, ofloxacin, penicillin, and nalidixic acid against $K$. pneumoniae (Table 2).

Antagonism action. For gram-positive bacteria, TQ showed antagonism against S. epidermidis ATCC 
Table 1 - Antibacterial activity of thymoquinone against pathogenic bacterial strains.

\begin{tabular}{|c|c|c|c|c|c|}
\hline \multirow[t]{3}{*}{ Organism } & \multirow[t]{3}{*}{ Origin } & \multicolumn{4}{|c|}{ Thymoquinone } \\
\hline & & \multirow{2}{*}{$\begin{array}{l}\text { Zone of inhibition } \\
\begin{array}{c}(50 \mu \mathrm{g} / \mathrm{ml}) \\
\mathrm{mm} \\
\text { Mean }(\mathrm{SD})\end{array}\end{array}$} & \multicolumn{3}{|c|}{$\mu \mathrm{g} / \mathrm{ml}$} \\
\hline & & & $\begin{array}{c}\text { MIC } \\
\text { Mean (SD) }\end{array}$ & & $\begin{array}{l}\text { MBC } \\
\text { ean (SD) }\end{array}$ \\
\hline \multicolumn{6}{|l|}{ Gram negative bacteria } \\
\hline Pseudomonas aeruginosa (ATCC 27853) & ATCC & - & - & & - \\
\hline Escherichia coli (ATCC 25922) & ATCC & - & - & & - \\
\hline Pseudomonas & Clinical & - & - & & - \\
\hline Salmonella typhi & Clinical & - & - & & - \\
\hline Klebsiella pneumoniae & Clinical & $15 \quad(2)$ & $1.30(0.45)$ & 33.33 & $(14.43)$ \\
\hline Shigella & Clinical & - & - & & - \\
\hline Escherichia coli & Clinical & - & - & & - \\
\hline \multicolumn{6}{|l|}{ Gram positive bacteria } \\
\hline Enterococcus faecalis (ATCC 29212) & ATCC & - & - & & - \\
\hline Staphylococcus epidermidis (ATCC 12228) & ATCC & $17(1.73)$ & $1.04(0.45)$ & 10.41 & $(3.60)$ \\
\hline Mycobacterium smegmatis & Clinical & - & - & & - \\
\hline Staphylococcus aureus & Clinical & $15 \quad(1)$ & $2.60(0.90)$ & & $(14.43)$ \\
\hline Staphylococcus saprophyticus & Clinical & - & - & & - \\
\hline Staphylococcus epidermidis & Clinical & $13(1.73)$ & $8.3(3.60)$ & 66.66 & $(28.86)$ \\
\hline Streptococcus pyogenes & Clinical & - & - & & - \\
\hline
\end{tabular}
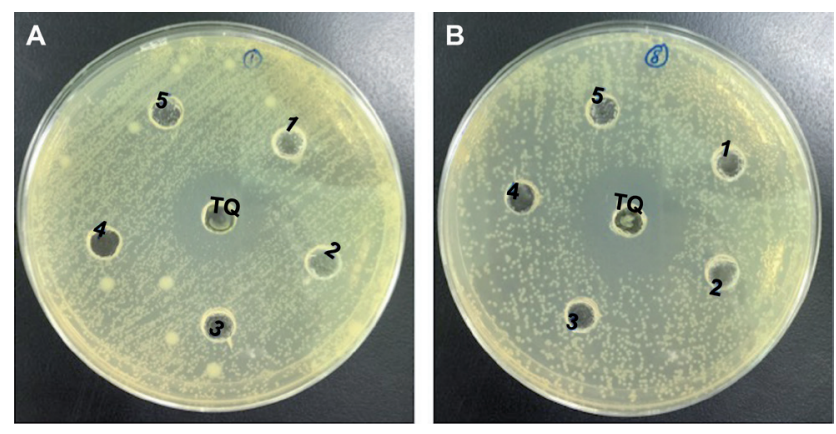

Figure 1 - Antibacterial activity of TQ. A) Antibacterial acitivity of thymoquinone (TQ) against Klebsiella pneumoniae. B) Antibacterial acitivity of TQ against Staphylococcus epidermidis (ATCC 1228).

12228 when combined with ofloxacin, tetracycline, and chloramphenicol; $S$. aureus with penicillin; and $S$. epidermidis with tetracycline and chloramphenicol. However, for gram-negative bacteria, TQ antagonism was not detected against $K$. pneumonia in combination with any of the tested antibiotics (Table 2).

Additive action. For gram-positive bacteria, TQ showed additive action with nalidixic acid against $S$. epidermidis ATCC 12228 and with gentamicin and nalidixic acid against $S$. aureus and $S$. epidermidis.
For gram-negative bacteria, TQ showed additive action with tetracycline and chloramphenicol against $K$. pneumoniae. Most of the results are same during each trial and there were no any significant difference observed with $\alpha=0.05$.

Disruption of bacterial cells visualized by SEM. Scanning electron microscopy was used to observed changes in the structural morphology of $S$. epidermidis in response to TQ (Figure 2). In the absence of TQ (control), the cells showed characteristic normal morphology (Figure 2A). Unlike the control, the cells that were treated with TQ had damaged cell membranes, showing that TQ treatment reduced the synthesis of extracellular polysaccharides (Figure 2B).

Thymoquinone inhibits bacterial adhesion. Adhesion assays were performed using Alamar blue dye to assess the effect of TQ on bacterial adherence. The bacterial cells showed inconsistent inhibition of adherence following exposure to various TQ concentrations, and this was concentration-dependent. For $K$. pneumoniae, S. epidermidis (ATCC 12228), S. aureus, and S. epidermidis, TQ inhibited bacterial adhesion by $39 \%-54 \%$ at $0.5 \times \mathrm{MIC}, 48 \%-68 \%$ at $1 \times \mathrm{MIC}$, and $61 \%-81 \%$ at $2 \times$ MIC (Figure 3), indicating that TQ was extremely efficient in diminishing adhesion of the tested bacteria, even at subinhibitory concentrations. 
Table 2 - Aynergistic antimicrobial activity of thymoquinone (TQ) with different antimicrobial agents.

\begin{tabular}{|c|c|c|c|c|c|c|c|}
\hline Bacteria & Antimicrobial agent & $\begin{array}{r}\text { Mean } \\
\text { zone wi } \\
\text { Mr }\end{array}$ & $\begin{array}{l}\text { f inhibition } \\
\text { th antibiotics } \\
(\mathrm{mm}) \\
\operatorname{can}(\mathrm{SD})\end{array}$ & $\begin{array}{c}\text { Mean of inhibition } \\
\text { zone with } \mathrm{Tq} \\
(\mathrm{mm}) \\
\text { Mean }(\mathrm{SD})\end{array}$ & $\begin{array}{l}\text { Inhibition zone } \\
\text { with synergism } \\
\text { Mean (SD) }\end{array}$ & Outcome & $P$-value \\
\hline \multirow[t]{6}{*}{ Klebsiella pneumoniae } & Gentamicin & 20 & $(1.73)$ & \multirow{4}{*}{$15 \quad(2)$} & $37(3.60)$ & Synergism & 0.458 \\
\hline & Offloxacin & 17 & $(1.0)$ & & $34(1.73)$ & Synergism & 0.638 \\
\hline & Tetracycline & & 0 & & $15 \quad(1)$ & Additive & $\leq 0.001$ \\
\hline & Penicillin & 15 & (2) & & $34 \quad(2)$ & Synergism & 0.485 \\
\hline & Chloramphenicol & & 0 & \multirow{8}{*}{$17(1.73)$} & $15(1.73)$ & Additive & $\leq 0.001$ \\
\hline & Nalidixic acid & 3 & (1) & & $20 \quad(1)$ & Synergism & $\leq 0.001$ \\
\hline \multirow{6}{*}{$\begin{array}{l}\text { Staphylococcus } \\
\text { epidermidis (ATCC } \\
\text { 12228) }\end{array}$} & Gentamicin & 18 & (2) & & (1) & Synergism & 0.254 \\
\hline & Offloxacin & 25 & (3) & & (2) & Antagonism & 1.258 \\
\hline & Tetracycline & & 0 & & (2) & Antagonism & 0.458 \\
\hline & Penicillin & 18 & $(1.73)$ & & $37 \quad(3.6)$ & Synergism & 0.471 \\
\hline & Chloramphenicol & 25 & (1) & & $36 \quad(1)$ & Antagonism & 0.689 \\
\hline & Nalidixic acid & & 0 & & $17(2.64)$ & Additive & $\leq 0.001$ \\
\hline \multirow[t]{6}{*}{ Staphylococcus aureus } & Gentamicin & & 0 & \multirow{6}{*}{$15 \quad(1)$} & $15 \quad(2)$ & Additive & $\leq 0.001$ \\
\hline & Offloxacin & 13 & $(01)$ & & $30(1.73)$ & Synergism & 0.356 \\
\hline & Tetracycline & 4 & (2) & & $21 \quad(1)$ & Synergism & 0.095 \\
\hline & Penicillin & 16 & $(1.73)$ & & $27(1.73)$ & Antagonism & 0.245 \\
\hline & Chloramphenicol & 18 & (2) & & $35 \quad(2)$ & Synergism & 0.325 \\
\hline & Nalidixic acid & 2 & (1) & & (1) & Additive & $\leq 0.001$ \\
\hline \multirow{6}{*}{$\begin{array}{l}\text { Staphylococcus } \\
\text { epidermidis }\end{array}$} & Gentamicin & 18 & $(1.73)$ & \multirow{6}{*}{$13(1.73)$} & $31 \quad(3.6)$ & Additive & 0.471 \\
\hline & Offloxacin & 17 & $(2.64)$ & & (2) & Synergism & 0.247 \\
\hline & Tetracycline & 18 & (1) & & (1) & Antagonism & 1.784 \\
\hline & Penicillin & 3 & (1) & & $21 \quad(1)$ & Synergism & $\leq 0.001$ \\
\hline & Chloramphenicol & 20 & (2) & & $26(1.73)$ & Antagonism & 0.478 \\
\hline & Nalidixic acid & & 0 & & $13(2.64)$ & Additive & $\leq 0.001$ \\
\hline
\end{tabular}
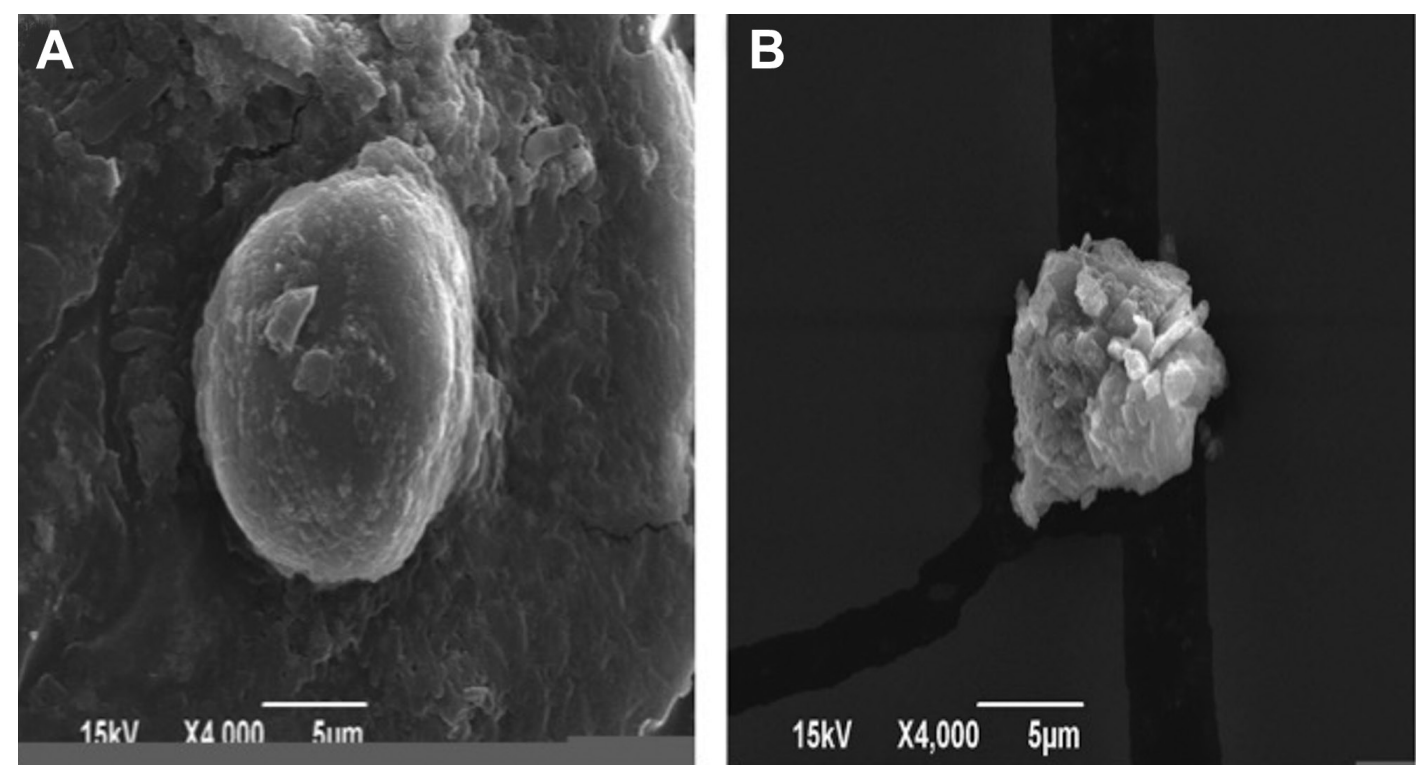

Figure 2 - Effect of thymoquinone (TQ) on cell morphology of Staphylococcus epidermidis. Changes in the cellular morphology were observed by scanning electron microscopy. A) Control cell B) shows bacterial cell treated with TQ. 
Thymoquinone inhibits bacterial biofilm formation. TQ treatment at $0.5 \times$ MIC, $1 \times$ MIC, and $2 \times$ MIC significantly inhibited biofilm formation in K. pneumoniae, S. epidermidis (ATCC 12228), S. aureus, and $S$. epidermidis by $31 \%-45 \%, 41 \%-59 \%$, and $58 \%-81 \%$, respectively, after $24 \mathrm{~h}$ and by $21 \%-34 \%$, $30 \%-51 \%$, and $44 \%-67 \%$, respectively, after $48 \mathrm{~h}$ (Figure 4). The rate of biofilm formation inhibition by TQ was concentration- and time-dependent.

Discussion. Thymoquinone is one of the most bioactive components of $N$. sativa and has diverse beneficial properties. Regarding antimicrobial effects, TQ has a broad-spectrum efficacy encompassing gram-negative and gram-positive bacteria. ${ }^{27}$ Thymoquinone also exhibits a synergistic effect with gentamicin and streptomycin and an additive effect with spectinomycin, doxycycline, tobramycin, erythromycin, chloramphenicol, ampicillin, lincomycin, nalidixic acid, and a combination of sulfamethoxazole and trimethoprim. ${ }^{21,27}$ In our study, TQ exhibited synergism in combination with gentamicin $(p=0.254)$ and penicillin $(p=0.471)$ against gram-positive $S$. epidermidis (ATCC 12228). Other studies have reported a similar effect

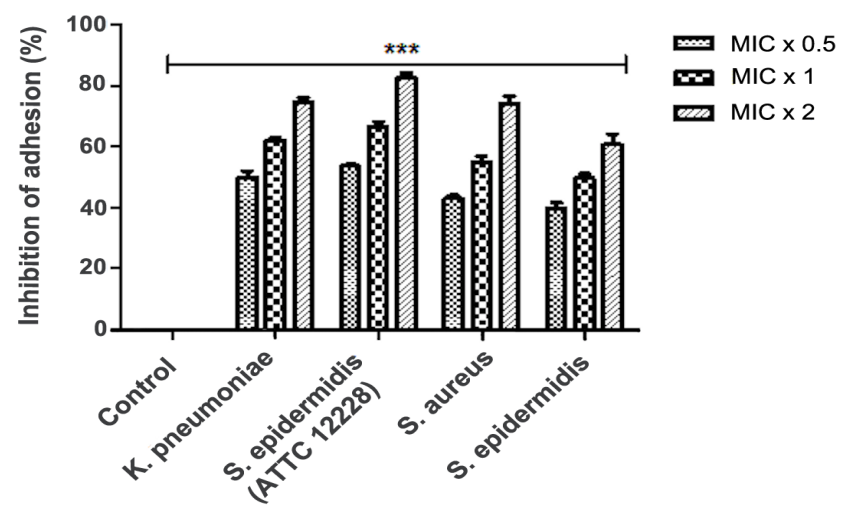

Figure 3 - Thymoquinone (TQ) inhibits bacterial adhesion. Alamar Blue based polystyrene adhesion assay was used to evaluate the effect of TQ on Klebsiella pneumoniae, Staphylococcus epidermidis (ATCC 12228), Staphylococcus aureus and Staphylococcus epidermidis adherence. All the tested bacterial strains were exposed to MIC x 0.5 , MIC x 1 and MIC x 2 values of TQ for $6 \mathrm{~h}$ at $37^{\circ} \mathrm{C}$. Control bars indicate all untreated bacterial strains, accepted as $0 \%$ inhibition. Results are presented from three independent experiments using means \pm SD ${ }^{* * *} p<0.0001$.

A

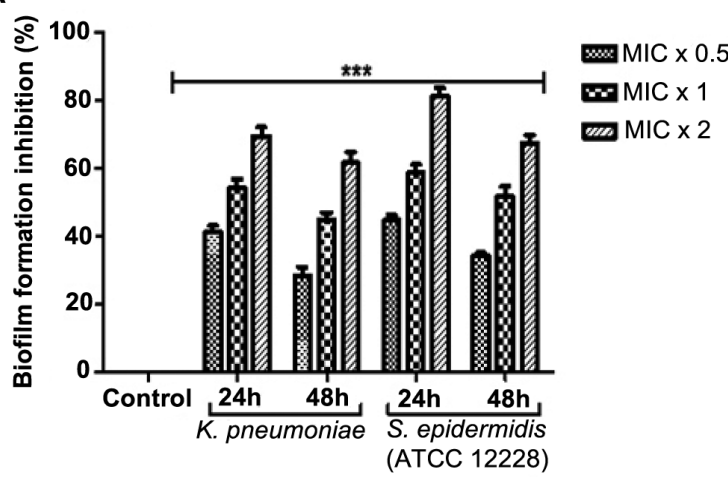

B

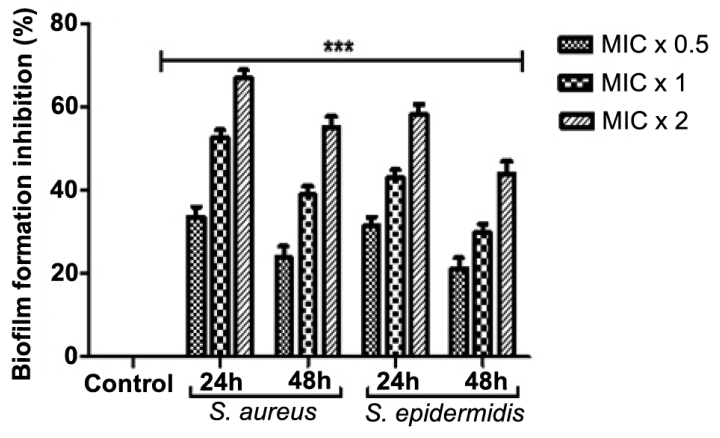

Figure 4 - Thymoquinone (TQ) reduces biofilm formation. A) Klebsiella pneumoniae and Staphylococcus epidermidis (ATCC 12228), B) Staphylococcus aureus and Staphylococcus epidermidis were incubated with MIC x 0.5, MIC x 1 and MIC x 2 values of TQ under biofilm growing conditions for 24 and $48 \mathrm{~h}$. Control bars indicate all untreated bacterial strains, accepted as $0 \%$ inhibition. Results are presented from 3 independent experiments using means $\pm S D{ }^{* * *} p<0.0001$. 
against $S$. epidermidis in combination with ofloxacin and penicillin. Furthermore, S. epidermidis strains were reported as resistant to more than one antibiotic, and S. epidermidis isolates were also more sensitive to ofloxacin and gentamycin. Combined with antibiotics, these natural extracts showed significant synergy, and the maximum synergistic effect was detected with cephalexin and erythromycin. ${ }^{30-32}$

Methicillin-resistant $S$. aureus is the most common pathogen encountered in clinical and laboratory settings. ${ }^{27}$ Previous studies have suggested that TQ in combination with antibiotics, such as cephalexin, ampicillin, tetracycline, gentamicin, and chloramphenicol, may show synergistic activity against S. aureus. ${ }^{23}$ Our observations agreed with the literature, as TQ showed a synergistic effect with ofloxacin, tetracycline, and chloramphenicol against $S$. aureus. ${ }^{7,27}$ Furthermore, our observations are supported by a report of TQ increasing the anti-staphylococcal effect of penicillin, tetracycline, and oxacillin against resistant bacterial strains. ${ }^{33}$

The MIC values that we observed for TQ against $K$. pneumoniae were much higher than those in wild-type $E$. coli. Therefore, it is evident that $K$. pneumoniae is highly resistant to several antimicrobial agents. Multidrug-resistant efflux pumps are the most important mechanisms through which bacteria can resist antibiotics, most notably tetracyclines. ${ }^{33}$ This pump expels multiple drugs and could play a role in multidrug resistance. ${ }^{34}$ To the best of our knowledge, there is a lack of literature on TQ synergistic studies with antibiotics against $K$. pneumoniae. In our study, TQ was synergistic with gentamicin $(p=0.458)$, ofloxacin ( $p=0.638)$, penicillin $(p=0.485)$, and nalidixic acid $(p \leq 0.001)$ against gram-negative $K$. pneumoniae. Thymoquinone has been reported to exert antibacterial activity against both gram-positive and gram-negative bacteria. Furthermore, MDR clinical strains of Shigella flexneri, S. typhimurium, S. aureus, and S. enteritidis were reported with TQ sensitivity similar to that of non-MDR strains, and the susceptibility of resistant bacterial isolates to TQ has been reported. ${ }^{35}$ Clinical isolates of $S$. aureus are often resistant to nearly all of the frequently used antimicrobials, including macrolides, aminoglycosides, chloramphenicol, fluoroquinolones, and tetracycline. ${ }^{36}$ Our study demonstrated that TQ exerts synergistic lethal effects against both gramnegative and gram-positive bacteria when combined with antibiotics. Therefore, TQ could be used as an antibacterial drug.

Efflux pumps are a bacterial defense mechanism that eliminates antibiotics from the cell. The action of the efflux pumps often predisposes the progression of microorganisms toward being highly resistant to antimicrobials. ${ }^{37,38}$ Some investigations have demonstrated the vital function of phytochemistry to explore the effectiveness of efflux pump inhibitors, particularly against gram-positive bacteria such as $S$. epidermidis and $S$. aureus. ${ }^{30}$ It was also reported that TQ could inhibit efflux pumps, consequently enhancing the concentration of 4',6-diamidino-2phenylindole in the cells. ${ }^{38}$ Hence, we hypothesize that this potential mechanism could also play a role in the anti-staphylococcal activity of TQ-tetracycline in combination with antibiotics, which is consistent with our study results. In contrast, -lactams are generally responsible for staphylococcal resistance by producing modified penicillin-binding proteins (PBPs) with decreased binding properties to antimicrobial agents. ${ }^{39}$ Therefore, it has been suggested that TQ may play a role in inhibiting PBPs responsible for staphylococcal resistance. ${ }^{34}$ Previous findings demonstrated that TQ could be an effective compound in combination with other antimicrobials against many bacterial strains, especially Staphylococcus sp. However, further investigations are necessary to examine their practical application. ${ }^{40}$

The capability of bacteria to adhere and form biofilm is responsible for their virulence. Our study revealed that TQ inhibited bacterial adhesion and biofilm formation. Adhesion properties are directly related to biofilm formation and lead to plaque formation. Bacterial cells have specialized proteins (adhesins) that encode host cell surface glycoproteins, enabling bacteria to adhere to host cells. ${ }^{41}$ We found that TQ significantly inhibited adherence by 39\%-81\% in a dose-dependent manner in $K$. pneumoniae, S. epidermidis (ATCC 12228), S. aureus, and S. epidermidis, and adherence to host tissue lead to biofilm formation in these strains. Biofilm is a vital virulence factor in periodontal bacteria. It enhances resistance to most conventional antibacterial drugs. ${ }^{42}$ Furthermore, there are numerous reports that biofilms are more resistant than planktonic cells to existing antimicrobials. ${ }^{43}$ In our study, TQ treatment significantly suppressed biofilm formation in a concentration-dependent manner by 31\%-81\% for $24 \mathrm{~h}$ and $21 \%-67 \%$ for $48 \mathrm{~h}$. Our findings support the assumption that TQ targets membrane adhesion proteins to inhibit adherence to host cells, subsequently inhibiting biofilm formation.

In conclusion, our study demonstrates that TQ can enhance the antibacterial activity of some antimicrobials. As demonstrated in Table 1, TQ was found more efficient anti-bacterial activities particularly 
against gram-positive bacteria. Although our findings provide new insights into possible mechanistic scenarios associated with the combinatory effect of TQ with antimicrobials. Further investigations are necessary to facilitate the development of novel therapeutic strategies using TQ against resistant microbes.

Acknowledgment. The authors are thankful to the Deanship of Scientific Research, King Khalid University, Abha, Kingdom of Saudi Arabia, for financially supporting this work through the General Research Project under (grant number G.R.P-3-40). The authors also thank the Deanship of Scientific Research and Researcher's Services \& Support Unit, King Saud University, Riyadh, Kingdom of Saudi Arabia for their technical support. The authors also acknowledge Enago (www.enago.com) for English language editing.

\section{References}

1. Abdallah EM. Black seed (Nigella sativa) as antimicrobial drug: a mini-Review. Nov Appro Drug Des Dev 2017; 3: 555603.

2. Gold HS, Moellering RC. Antimicrobial-drug resistance. $N$ Engl J Med 1996; 335: 1445-1453.

3. Bajera T, Silha D, Ventura K, Bajerov P. Composition and antimicrobial activity of the essential oil, distilled aromatic water and herbal infusion from Epilobium parviflorum Schreb. Ind Crops Prod 2017; 100: 95-105.

4. Sonam C, Sharma K, Guleria S. Antimicrobial activity of some essential oils - present status and future perspectives. Medicines (Basel) 2017: 4: 58.

5. Okeke IN, Laxminarayan R, Bhutta ZA, Duse A, Jenkins P, O’Brien T, et al. Antimicrobial resistance in developing countries. Part I: recent trends and current status. Lancet Infect Dis 2005; 5: 481-493.

6. Neu HC. The crisis in antibiotic resistance. Science 1992; 257 : 1064-1073.

7. Eman H. Antibacterial activity of thymoquinone and thymohydroquinone of Nigella sativa $L$. and their interaction with some antibiotics. Adv Biol Res 2009; 3: 148-152.

8. Drago L, De Vecchi E, Nicola L. In vitro evaluation of antibiotics' combinations for empirical therapy of suspected methicillin resistant Staphylococcus aureus severe respiratory infections. BMC Infect Dis 2007; 7: 111.

9. Hemaiswarya S, Kruthiventi AK, Doble M. Synergism between natural products and antibiotics against infectious diseases. Phytomedicine 2008; 15: 639-652.

10. Mouwakeh A, Telbisz A, Spengler G, Mohácsi-Farkas C, Kiskó G. Antibacterial and resistance modifying activities of Nigella sativa essential oil and its active compounds against Listeria monocytogenes. In Vivo 2018; 32: 737-743.

11. Kokoska L. Chemistry and biological activity of Nigella genus: the antimicrobial and anti-inflammatory effects of seed extracts, essential oils and compounds of six Nigella species. Germany: LAP LAMBERT Academic Publishing; 2011.

12. Randhawa MA, Al-Ghamdi MS. A review of the pharmacotherapeutic effects of Nigella sativa. Pak J Med Res.2020; 41: 77-83.

13. Dera A, Rajagopalan P. Thymoquinone attenuates phosphorylation of AKT to inhibit kidney cancer cell proliferation. J Food Biochem 2019; 43: e12793.
14. Dera AA, Rajagopalan P, Alfhili MA, Ahmed I, Chandramoorthy HC. Thymoquinone attenuates oxidative stress of kidney mitochondria and exerts nephroprotective effects in oxonic acid-induced hyperuricemia rats. Biofactors 2019; 46: 292-300.

15. Dera A, Rajagopalan P, Ahmed I, Alfhili M, Alsughayyir J, Chandramoorthy HC. Thymoquinone attenuates IgE-mediated allergic response via pi3k-Akt-NFKB pathway and upregulation of the Nrf2-HO1 axis. J Food Biochem 2020; 44: e13216.

16. Dera AA, Rajagopalan P, Al Fayi M, Ahmed I, Chandramoorthy HC. Indirubin-3-monoxime and thymoquinone exhibit synergistic efficacy as therapeutic combination in in-vitro and in-vivo models of lung cancer. Arch. Pharm Res 2020; 43: 655-665.

17. Asaduzzaman K, Tania M, Shangyi FU, Junjiang FU. (2017) Thymoquinone, as an anticancer molecule: from basic research to clinical investigation. Oncotarget 2017; 8: 51907-51919.

18. Bakathir HA, Abbas NA. Detection of the Antibacterial Effect of Nigella Sativa Ground Seeds with Water. Afr J Tradit Complement Altern Med 2011; 8: 159-164.

19. Randhawa MA, Alenazy AK, Alrowaili MG, Basha J. An active principle of Nigella sativa L., thymoquinone, showing significant antimicrobial activity against anaerobic bacteria. $J$ Intercult Ethnopharmacol 2017; 6: 97-101.

20. El-Fatatry HM. Isolation and structure assignment of an antimicrobial principle from the volatile oil of Nigella sativa $L$ seeds. Pharmazie 1975; 30: 109-111.

21. Hanafi MS, Hatem ME. Studies on the anti-microbial activity of the Nigella sativa seed (Black Cumin). J Ethnopharmacol 1991; 34: 275-278.

22. Morsi NM. Antimicrobial effect of crude extracts of Nigella sativa on multiple antibiotic resistant bacteria. Acta Microbiologica Polonica 2000; 49: 63-74.

23. Goyal SN, Prajapati CP, Gore PR, Patil CR, Mahajan UB, Sharma C. Therapeutic potential and pharmaceutical development of thymoquinone: a multitargeted molecule of natural origin. Front Pharmacol 2017; 8: 656.

24. Saquib SA, Al Qahtani NA, Ahmad I, Kader MA, Al Shahrani SS, Asiri EA. Evaluation and comparison of antibacterial efficacy of herbal extracts in combination with antibiotics on periodontal pathobionts: an in vitro microbiological study. Antibiotics 2019; 8: 89.

25. Nussdorfer P, Cilenšek I, Zorn B, Petrovic D. Adapted methods for scanning electron microscopy (SEM) in assessment of human sperm morphology. Bosn J Basic Med Sci 2018; 18: 43-48.

26. Eid RA, Alkhateeb MA, Al-Shraim M, Eleawa SM, Shatoor AS, El-Kott AF, et al. Ghrelin prevents cardiac cell apoptosis during cardiac remodelling post experimentally induced myocardial infarction in rats via activation of Raf-MEK1/2-ERK1/2 signalling. Arch Physiol Biochem 2019 125: 93-103.

27. Forouzanfar F, Fazly Bazzaz BS, Hosseinzadeh H. Black cumin (Nigella sativa) and its constituent (thymoquinone): a review on antimicrobial effects. Iran J Basic Med Sci 2014; 17: 929-938.

28. Raut JS, Shinde RB, Chauhan, NM, Karuppayil SM. Terpenoids of plant origin inhibit morphogenesis, adhesion, and biofilm formation by Candida albicans. Biofouling 2013; 29: 87-96.

29. Jin Y, Samaranayake LP, Samaranayake Y, Yip HK. Biofilm formation of Candida albicans is variably affected by saliva and dietary sugars. Arch Oral 2004; 49: 789-798. 
30. Abidi SH, Ahmed K, Sherwani SK, Kazmi SU. Synergy between antibiotics and natural agents results in increased antimicrobial activity against Staphylococcus epidermidis. J Infect Dev Countr 2015; 9: 925-929.

31. Dodou HV, de Morais Batista AH, Sales GWP, de Medeiros SC, Rodrigues ML, Nogueira PCN, et al. Violacein antimicrobial activity on Staphylococcus epidermidis and synergistic effect on commercially available antibiotics. J Appl Microbiol 2017; 123: 853-860.

32. Kiari FZ, Meddah B, Meddah AT. (In vitro study on the activity of essential oil and methanolic extract from Algerian Nigella sativa L. Seeds on the growth kinetics of micro-organisms isolated from the buccal cavities of periodontal patients. Saudi Dent J 2018; 30: 312-323.

33. Piddock LJV. Clinically relevant chromosomally encoded multidrug resistance efflux pumps in bacteria. Clin Microbiol Rev 2006; 19: 382-382.

34. Johana R, Pavel N, Urban J, Kokoska L. Determination of anti-staphylococcal activity of thymoquinone in combinations with antibiotics by checkerboard method using EVA capmat as a vapor barrier. Arab J Chem 2017; 10: 566-572.

35. Ogawa W, Li DW, Ping YU, Begum A, Mizushima T, Kuroda T. Multidrug resistance in Klebsiella pneumoniae MGH78578 and cloning of genes responsible for the resistance. Biol Pharm Bull 2005; 28: 1505-1508.

36. Salman MT, Khan RA, Shukla J. Antimicrobial activity of Nigella sativa Linn. seed oil against multi-drug resistant bacteria from clinical isolates. Nat Prod Radiance 2008; 7: 10-14.
37. Mandell G, Douglas J., Bennett R. (1995) Principles and practices of infectious diseases, 4th ed. Edinburgh (UK): Churchill Livingstone; 1995. p. 80-112.

38. Handzlik J, Matys A, Kieć-Kononowicz K. Recent advances in multi-drug resistance (MDR) efflux pump inhibitors of Grampositive bacteria S. aureus. Antibiotics (Basel) 2013; 2: 28-45.

39. Kouidhi B., Zmantar T., Jrah H., Souiden Y., Chaieb K., Mahdouani K. Antibacterial and resistance modifying activities of thymoquinone against oral pathogens. Ann Clin Microbiol Antimicrob 2011; 10: 29.

40. Macheboeuf P, Contreras-Martel C, Job V, Dideberg O, Dessen A. Penicillin binding proteins: key players in bacterial cell cycle and drug resistance processes. FEMS Microbiol Rev 2006; 30 : 673-691.

41. Steinberg D. Studying plaque biofilms on various dental surfaces. In: An YH, Friedman RJ, editors. Handbook of bacterial adhesion: principles, methods, and applications. Totowa (NJ): Humana Press; 2000. p. 353-370.

42. Cazzaniga G, Ottobelli M, Ionescu A, Garcia-Godoy F, Brambilla E. Surface properties of resin-based composite materials and biofilm formation: a review of the current literature. Am J Dent 2015; 28: 311-320.

43. Marsh PD. Dental plaque as a biofilm and a microbial community-implications for health and disease. BMC Oral Health. 2006; 6: S14. 